\title{
Cocaine, ethanol, cannabis and benzodiazepines co-consumption among patients assisted at the emergency room
}

This article was published in the following Dove Press journal: Open Access Emergency Medicine

\author{
Aníbal A Teherán' \\ Luis M Pombo' \\ Vanessa Cadavid' \\ María C Mejía' \\ Jaime F La Rota ${ }^{2}$ \\ Juan $C$ Hernández ${ }^{3}$ \\ Norma Montoya ${ }^{4}$ \\ Thalia S López ${ }^{3}$ \\ 'Research Center, Juan N. Corpas \\ University, Bogota, Colombia; \\ ${ }^{2}$ Toxicology Department, Santa Clara \\ Hospital, Bogota, Colombia; ${ }^{3}$ Emergency \\ Deparment, Clínica de Occidente, \\ Bogota, Colombia; ${ }^{4}$ Clinical Laboratory, \\ Clínica de Occidente S.A., Bogota, \\ Colombia
}

Introduction: Cocaine and ethanol $(\mathrm{EtOH})$ co-consumption is a risk factor for physiologically and clinically negative outcomes. We describe the occurrence of cocaine consumption alone or co-consumption with EtOH and others psychotropics.

Patients and methods: The descriptive research used data on medical records of patients positive to cocaine test who attended an emergency room between 2016 and 2017. We determined the frequency of cocaine consumption alone and co-consumption with EtOH, cannabis or benzodiazepines (BZDs).

Results: Over one year period, 88 patients (13.3\%) were positive to cocaine test, mainly attended on weekends, in holiday months, young adults or men. Among those positive for cocaine, $72 \%$ were also positive for $\mathrm{EtOH}$, cannabis or BZD. Cocaine co-consumption with one or two out of three substance was 55.2\% (CI95\%; 44.7-65.8\%) and 16.4\% (CI95\%;8.58$24.3 \%$ ), respectively. Co-consumption was more frecuently wih $\mathrm{EtOH}$, followed by cannabis or BZD.

Conclusion: Co-consumption of cocaine with EtOH is very common and could be associated with acute or chronic consumption of cannabis or acute exposure to BZDs. It is important that emergency physicians use a systematic approach to diagnose and treat more than one psychotropic substance in cocaine positive patients.

Keywords: cocaine, ethanol, emergency room, cannabis, co-consumption, psychotropic substance

\section{Introduction}

Since the 1990s, cocaine intoxication has been of interest for scientific and clinician; From 1975 to 2015, so far over 2000 articles have been published about acute cocaine poisoning, possibly due to the negative impact on Public Health. ${ }^{1}$

A research conducted in city residents visiting the ER in Chicago stablished that, followed to ethanol $(\mathrm{EtOH})$ intoxication, acute cocaine intoxication was the most prevalent diagnosis $(31.7 \%)$ and, leastwise, $5 \%$ consumed heroin concurrently. ${ }^{2}$

In Colombia at least 2 million people reported having consumed EtOH throughout the last month, being the most frequently used psychoactive substance. Furthermore, following marijuana, cocaine was the most consumed illicit substance, but no data was founded about co-consumption of cocaine with EtOH or other psychotropic substances. 3 ,

Animal models have established that combined use of cocaine and EtOH increased significantly the mortality in mice from $40 \%$ in the control group to $86 \%$
Correspondence: Vanessa Cadavid

Research Center, Juan N. Corpas University

Carerra III \# 159 A - 6I - Fundación

Bogota, Colombia

Tel +57 I 6622222

Email cadavid-vanessa@juanncorpas.edu.co 
in the experimental group. ${ }^{5}$ In humans, cocaine is hydrolyzed to benzoylecgonine and to ecgonine methyl ester or demethylated to norcocaine. However, when consumed in combination with $\mathrm{EtOH}$, a significant amount of cocaine is converted to cocaethylene. ${ }^{6}$ This has proven to be more lethal than cocaine and its frequent combination with EtOH has been associated with an increased risk of sudden death, than with cocaine alone. ${ }^{7}$ The combination of EtOH and cocaine heightens the effects of both substances, prolongs the agitation and paranoia induced by cocaine and contributes to the toxicity associated with excessive consumption. ${ }^{8}$ Also, it has been proven that the presence of cocaethylene in urine increases five times the risk of requiring assistant care at the Intensive Care Unit (ICU). ${ }^{9}$ Human experiments have shown that the use of cocaine increases the cardiovascular response with higher heart rate (HR) and blood pressure (BP); EtOH increases HR and decreases BP, while co-consumption increases the HR by four times. ${ }^{10}$

In Colombia, the teenage population ( $\geq 12$ years old) hold a higher risk to consume cocaine along with other psychoactive substances. ${ }^{11}$ In addition, in urban areas such as large cities, marijuana $(51.3 \%)$, cocaine base paste (32.8\%), ecstasy (MDMA) (25.0\%) and heroin (14.1\%) can be easily consumed due to its low cost. ${ }^{3}$ While one kilogram of cocaine is approximately $\$ 1,000$ USD in Colombia, the cost in Asia is around $\$ 170,000$ USD. $^{12}$ In a retrospective cohort of patients positive for psychoactive substances admitted to ER, described that trauma cases were significantly more frequently for patients that consumed both EtOH and cocaine, compared to patients that consumed cocaine alone. ${ }^{13}$

Given the latent, social and physiologically risk attributed to cocaine consumption, alone or concurrent with other drugs, we measure the frequency of patients positive to a test for cocaine, that simultaneously was identified as positive to $\mathrm{EtOH}$ use or other psychoactive substances at the ER.

\section{Materials and methods \\ Design and patient's selection}

A retrospective descriptive analysis using the medical records of patients presenting between January 2016 to December 2017 to the ER of an IV level health institution (Clínica del Occidente S.A. [CDO]). Patients positive for cocaine in a urine test were included, and patients with incomplete demographic information or lacking data about the co-consumption with other psychotropic substances were excluded.

Only the information contained in the medical records was used, the anonymity and confidentiality of data were preserved, so this research it was classified as "Without risk" according to Resolution 008930 from 1993 on ethical aspects regarding research done in Colombia. Therefore, it only required the approval of the Research Committee of CDO (730 and 027).

\section{Database and variables}

The clinical laboratory of CDO provided a preliminary database containing patients with positive or negative results from a urine screening for cocaine and dates on which the test was done. Two researchers (AJC, LTS) collected data and who did not intervene in the analysis of data. Patient's identifications were changed using ascending consecutive number, from the first to the last patient try out positive for cocaine.

Demographic variables as age, sex and date of attention were included; the date and time of attention were transformed into stationary variables, specifically and month of occurrence; to define the weekend and nights, we used a definition that applies to the local schedule and includes all holidays. ${ }^{14}$

The clinical variables taken under consideration were positive results of urine and blood screening tests for cannabis, Benzodiazepines (BZD) and EtOH. In addition, we measured the time lapse between the admission to the ER and the taking of the toxicological tests to determine the opportunity of diagnosis (supplementary material).

\section{Collection and processing of samples for psychotropics}

The toxicology sample collection protocol established for Colombia was implemented for all patients, which requires the completion of two forms: 1) chain of custody; and 2) report of intoxication. ${ }^{15}$

A urine sample $\geq 2 \mathrm{~mL}$ was collected to identify the presence of cocaine, BZD or cannabis. These were processed according to the specifications established in the inserts for rapid testing of the respective substances (COC One Step cocaine test Device (urine) AbonBiopharm [Hangznou] Co., Ltd.; BZD RAPID TEST CASSETE (URINE) RightSignBiotesT [Hangznou] Co., Ltd.; THC RAPID TEST CASSETE (URINE) LUMIRATEK lumiraDx [Hangznou] Co., Ltd.). The three tests were 
classified as positive or negative, if by the end of 15 mins; one or two lines appeared, respectively, in the cassette's result verification section. To evaluate the concentration of EtOH in the blood $(\mathrm{mg} / 100 \mathrm{~mL})$, two samples were collected by accessing the vein (after cleaning the area with a non-alcoholic detergent). The first sample was drawn using a dry tube to run the tests within the institution (CDO) and the second was done using a tube containing an anticoagulant (calcium oxalate) solution, according to the collection of toxicological sample guidelines, and was sent to the District Health Secretary for evaluation; both were processed in two Roche - Hitachi machines: 1. COBAS c501, 2. COBAS 6000.

\section{Outcomes}

The frequency of cocaine consumption throughout the year was determined in any three scenarios: 1) exclusive cocaine consumption (alone); 2) combined cocaine consumption with EtOH; or 3) combined cocaine consumption with $\mathrm{EtOH}$, cannabis or BZD.

\section{Statistical analysis}

The statistical packages Minitab ${ }^{\circledR}$ version 18 (Minitab Inc, State College, PA, USA), and SPSS ${ }^{\circledR}$ version 25 (IBM Corporation, Armonk, NY, USA) were used to analyze the data. The qualitative data was measured in percentages while the quantitative data in medians; the monthly frequency for testing positive for cocaine in the three scenarios mentioned above was adjusted to $95 \% \mathrm{CI}$ since not all patients were given the same tests for $\mathrm{EtOH}$, cannabis or BZD. To compare two proportions $Z$ test was used, and three or more Chi-Square test; Non-parametric statistic was used to compare continuous variables. p-value $<0.05$ was established as significant.

\section{Results}

\section{General and stationary characteristics}

During 2016-2017, 661 urine tests for cocaine were performed, 88 tested positive for cocaine $(13.3 \%$; $95 \% \mathrm{CI}$, $10.8-16.1 \%$ ); three patients were excluded due to incomplete data. Men and young adults were the most frequent demographic characteristics present in the study. The monthly average visits to the ER was 12.816 patients, and the range oscillated between 10.358 and 15.850 emergencies that were attended in December-2017 and February-2016, respectively. Likewise, the monthly average of toxicological tests performed was 27 , and range oscillated between 16 and 48 tests by month (Table S1).

As the weekend approached, the frequency of patients with a cocaine positive test increased; When comparing the frequency of positive cocaine cases on Saturdays and Sunday's respect to Mondays the differences were $15.3 \%$ (CI95\%, 4.9-25.9\%; $p: 0.005)$ and 21.2\% (CI95\%, $10.2-$ $32.2 \%$; $p: 0.000)$ respectively. None differences were found between the frequency of cocaine positive cases on weekdays and weekend (data not shown) (Table 1); Moreover, the frequency of cocaine positive cases during holidays months (January-February, June-August, November-December), was higher compared to the working months (proportion differences: 17.6\%, 2.9-32.4\%: 0.021) (Table 1, Figure 1).

\section{Cocaine co-consumption with $\mathrm{EtOH}$, cannabis or BZD}

Nearly, three out of four cocaine-positive patients (CI95\%, $61.7-81.7 \%$ ) were also positive for one of the three

Table I Baseline characteristics

\begin{tabular}{|c|c|}
\hline Feature & Parameters \\
\hline Age, years old (25th -75 th) & $27(31-34)$ \\
\hline EtOH concentration, $\mathrm{mg} / \mathrm{I} 00 \mathrm{~mL}$ (25th -75 th) & $24.4(3|-| 3 \mid .4)$ \\
\hline $\mathrm{EtOH}$ processing time, minutes ( 25 th -75 th) & $252.5(165.5-433.5)$ \\
\hline \multicolumn{2}{|l|}{ Cases by month, $\mathrm{n}(\%, \mathrm{Cl} 95 \%)$} \\
\hline January & $8(9.4,4.6-17)$ \\
\hline February & $8(9.4,4.6-17)$ \\
\hline March & $4(4.7,1.6-10.8)$ \\
\hline April & $5(5.9,2.3-12-4)$ \\
\hline May & $6(7.1,3.0-14.0)$ \\
\hline June & $6(7.1,3.0-14.0)$ \\
\hline July & $7(8.2,3.8-15.5)$ \\
\hline August & $8(9.4,4.6-17.0)$ \\
\hline September & $6(7.1,3.0-14.0)$ \\
\hline October & $4(4.7,1.6-10.8)$ \\
\hline November & $10(11.8,6.2-19.9)$ \\
\hline December & $13(15.3,8.9-24)$ \\
\hline \multicolumn{2}{|l|}{ Cases by weekday, n (\%, Cl 95\%) } \\
\hline Monday & $6(7.1,3.0-14.0)$ \\
\hline Tuesday & $6(7.1,3.0-14.0)$ \\
\hline Wednesday & II (I2.9, 7.I-2I.3) \\
\hline Thursday & $10(11.8,6.2-19.9)$ \\
\hline Friday & $9(10.6,5.4-18.4)$ \\
\hline Saturday & $19(22.4,14.5-32)$ \\
\hline Sunday & $24(28.2,19.5-38.4)$ \\
\hline
\end{tabular}

Note: All quantitative variables were expressed in medians because normality was rejected (Kolmogorov Smirnov test). 


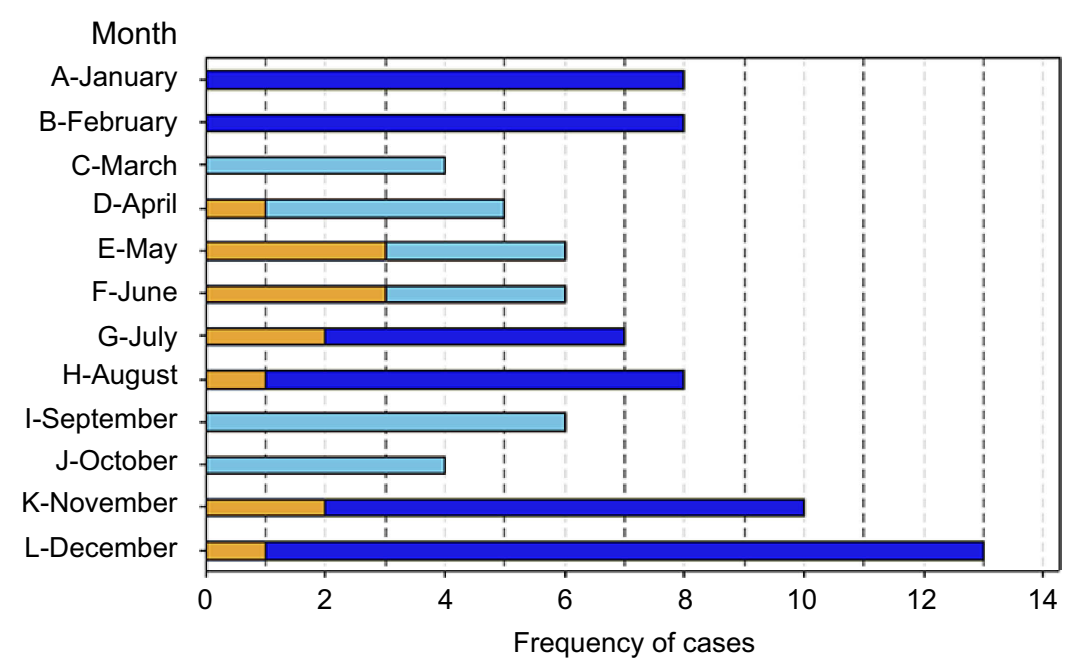

Figure I Frequency ( $\mathrm{n}$ ) of cocaine positive tests according to sex. Cases by months of year; light blue colour identifies male sex; orange identifies female sex; and dark blue identifies months with most frequency. Alphabet letters were used to order the months from January until December.

additionally measured psychotropic substances (EtOH, cannabis or BZD). During the period studied, cocaine co-consumption with $\mathrm{EtOH}$, cannabis or BZD was identified in 11 out of the 12 months of the year; simultaneous consumption (simple co-consumption) was identified with one of the psychotropic drugs (55.2\%, CI95\%, 44.7-65.8\%); 7 out of the 12 months, simultaneous consumption with two psychotropic drugs (double co-consumption, $16.4 \%$, CI $95 \%$ 8.58-24.3\%). The last pattern was identified as more frequent during the holiday months (Figure 2). Among the three tests for psychotropic drugs, BZD was the most requested, followed by cannabis, and lastly, EtOH. This last one, was the most consumed psychotropic substance in combination with cocaine, followed by cannabis and BZD (Table 2). A relationship between cocaine positive cases and males (with or without co-consumption) was established (Figure 3). Yet, there is no relationship with age, time of day, or weekends.

No correlation was found between EtOH concentration and age (Rho: $0.150, p: 0.249$ ) or between the time admission to the ER and running the lab work (Rho: 0.039; $p$ : 0.764). In addition, there were no differences in the EtOH concentration between cocaine or co-consumption users.

\section{Discussion}

This study described a high frequency of patients presenting to an ER, positive for cocaine and co-consumption

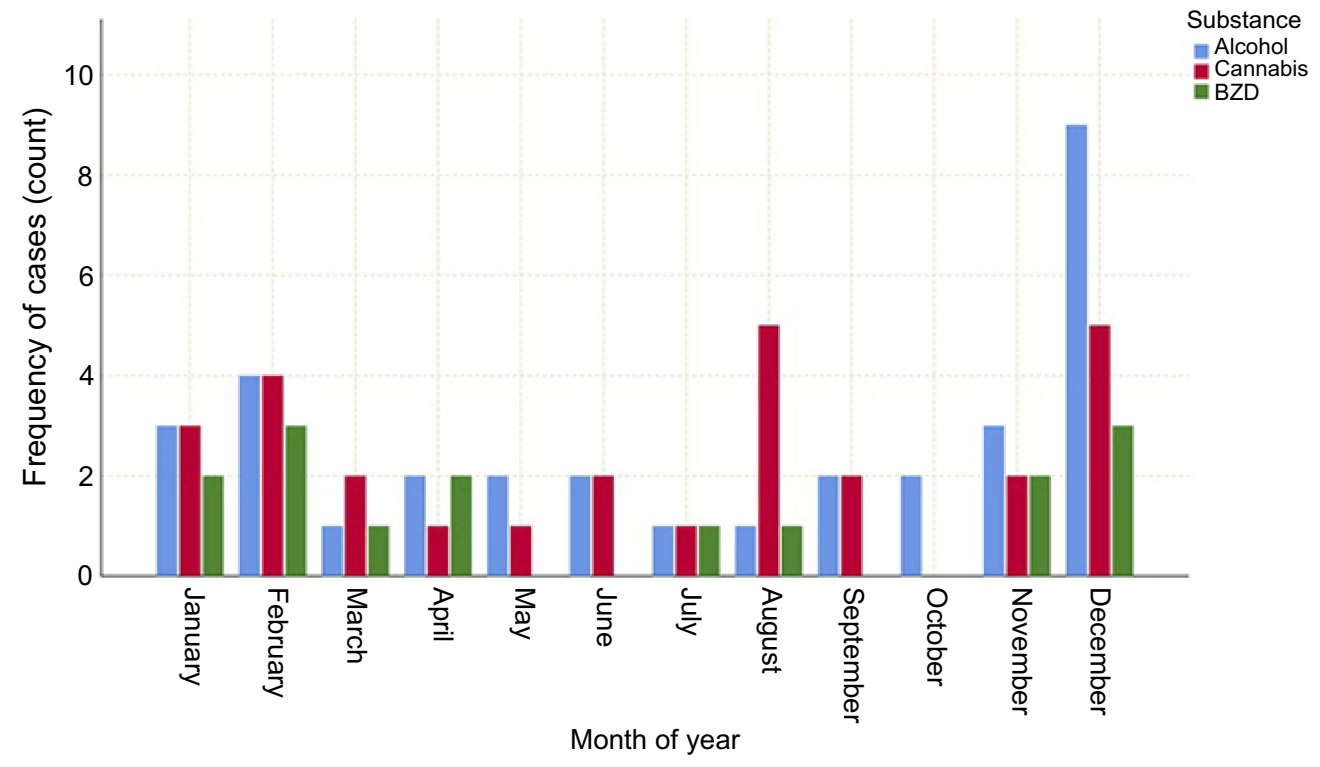

Figure 2 Co-consumption of cocaine and other psychotropics by month. This graph shows, throughout the months of the year, the frequency of patients positive to cocaine test and to cannabis, ethanol or benzodiazepines (BZD). 
Table 2 Positivity of substances among those screened for cocaine

\begin{tabular}{|c|c|c|c|c|c|c|c|c|c|c|c|c|c|}
\hline \multirow[t]{2}{*}{ Measure } & \multicolumn{2}{|c|}{ EtOH (n: 6I) } & \multirow[t]{2}{*}{ UN } & \multicolumn{2}{|c|}{ Cann (n: 76) } & \multirow[t]{2}{*}{ UN } & \multicolumn{2}{|c|}{ BZD (n: 78) } & \multirow[t]{2}{*}{ UN } & \multicolumn{2}{|c|}{ Any (n: 84) } & \multirow[t]{2}{*}{ UN } & \multirow[t]{2}{*}{ Overall cocaine } \\
\hline & $(+52.5)$ & $(-)$ & & $(+36.8)$ & $(-)$ & & $(+19.2)$ & $(-)$ & & $(+72.6)$ & $(-)$ & & \\
\hline \multicolumn{14}{|l|}{ Sex } \\
\hline Male & 28 & 24 & 20 & 26 & 37 & 9 & 15 & 50 & 7 & 55 & 16 & 1 & $72(84.7)$ \\
\hline Female & 4 & 5 & 4 & 2 & 11 & 0 & 0 & 13 & 0 & 6 & 7 & 0 & $13(15.3)$ \\
\hline \multicolumn{14}{|l|}{ Weekend } \\
\hline Yes & 23 & 12 & 13 & 16 & 26 & 6 & 7 & 35 & 6 & 37 & 10 & 1 & $48(56.5)$ \\
\hline Not & 9 & 17 & 11 & 12 & 22 & 3 & 8 & 28 & 1 & 24 & 13 & 0 & $37(43.5)$ \\
\hline \multicolumn{14}{|l|}{ Night } \\
\hline Yes & 13 & 10 & 8 & 12 & 15 & 4 & 7 & 23 & 1 & 24 & 7 & 0 & $31(36.5)$ \\
\hline Not & 19 & 19 & 16 & 16 & 33 & 5 & 8 & 40 & 6 & 37 & 16 & I & $54(63.5)$ \\
\hline Total & $32(37.6)$ & 29 & 24 & $28(32.9)$ & 48 & 9 & $15(17.6)$ & 63 & 7 & $6 \mid(7 \mid .8)$ & 23 & 1 & 85 \\
\hline
\end{tabular}

Note: The data in parentheses were expressed in percentages; the percentages next to positive signs were calculated by dividing the total patients positive for a specific substance between total screened patients for that substance and multiplied by 100; the percentages expressed in total row and in the last column were calculated by dividing the total patients positive for a specific substance between total patients positive for cocaine and multiplied by 100 .

Abbreviations: EtOH, ethanol; Cann, cannabis; BZD, benzodiazepines; Any, any of substances assessed; UN, unscreened.

with EtOH, BZD and cannabis. Likewise, it allowed us to identify some features related to the isolated use of cocaine or the co-consumption with other substances.

$\mathrm{CDO}$ is located at $1.4 \mathrm{~km}$ from a highly dense sports and social area which includes a conglomerate of entertainment and recreational centers, nightclubs, motels, prostitution, and liquor stores, predominantly active at weekends; ${ }^{16,17,21}$ it is also situated in one of the most densely populated areas in Bogota, where teenagers (14 years old) and adults (25-29 years old) are at the base of the population pyramid structure; ${ }^{18}$ the previous facts could be determining factors that

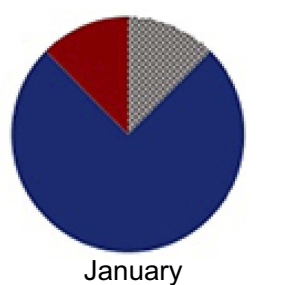

January
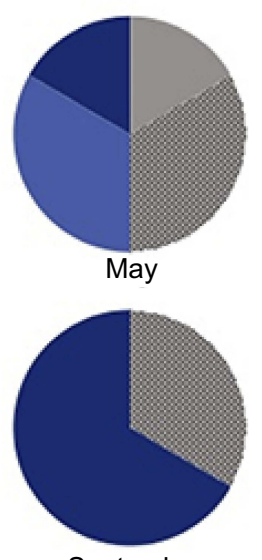

September

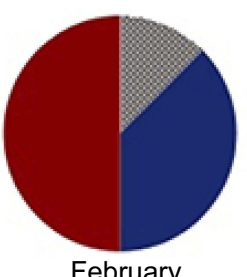

February
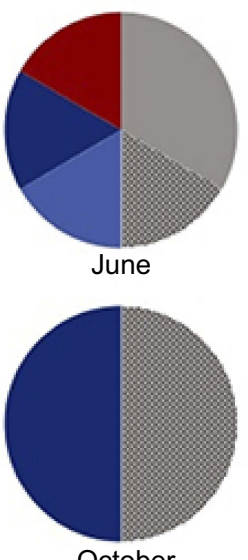

October

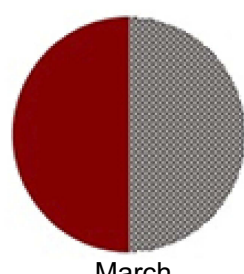

March

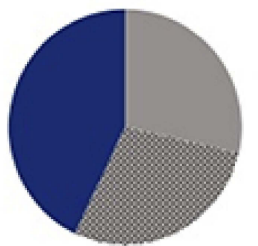

July

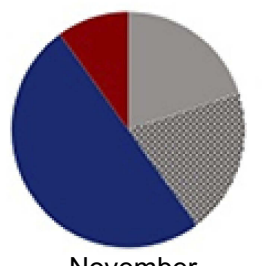

November

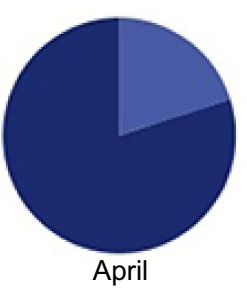

Cocaine alone and other substances Cocaine female Cocaine plus 1 female Cocaine plus 1 male Cocaine plus 2 male

Figure 3 Cocaine positive cases alone or co-consumption by months and sex. This figure represents the months of the year and the distribution by sex in which positive cocaine patients were identified as the only substance or in co-consumption with I or 2 additional substances. 
influence the frequency with which cocaine and EtOH are co-consumed; additionally, a high rate of street crime and micro-narcotic trafficking has been observed; BZD is used for criminal purposes since its physiological effect on the central nervous system, specifically the sedative one, allows the criminal to approach and submit subject to robbery, rape among other criminal behaviors. ${ }^{19,20}$ Probably, this explains the frequency of patients positive for cocaine consumption, mainly on the weekends described in this cases series. $^{22,23}$

Cocaine consumption in young-adult male patients, primarily in holidays months was more frequently identified; this agrees with reports from Latin America indicating that this is a problem for young men and teenagers, mainly at 31 years, in addition to low socioeconomic levels, ${ }^{24,25} \mathrm{~A}$ research conducted in Brazil, where $80 \%$ or more of people studied were 30 -year-old men in average (adult life cycle), most of them said they had used cocaine with other substances such as EtOH or tobacco. ${ }^{26,27}$

Is important to mention that, although male individuals predominated in this research and in most of the studies done, there are articles that consider that estrogen plays an important role in the proneness to addiction, thus it was expected to find that the percentage of female consumers would have been higher than that of men. ${ }^{28,29}$

The rapid testing's for substance abuse detection, such as those described in this study, to evaluate the presence of cocaine, BZD and cannabis, are a type of qualitative preliminary analytical tests. In general, they are accurate for concentrations close to the cut-off point; accuracy confirmed by more precise and reproducible analyzes, such as gas chromatography, in addition to, mass spectrometry (GC-MS). ${ }^{30}$ A positive result indicates the presence of the compound analyzed or its metabolites but does not provide information on how it was administered, the concentration of the drug in the urine or the last time of exposure, moreover cannabis and benzodiazepines can show positive with these tests for a long time after use. About this, only 1 of 15 patients positive for BZD mentioned a history of chronic use of Clonazepam to treat epilepsy, and another mentioned the chronic abuse of psychoactive drugs, but none in specific; It is worth mentioning that none of positive for BZD presented states of agitation upon admission, therefore none required management with a similar medication. We expected that the presence of cannabis (positive) could be related to consumption during last month, and 13/18 mentioned chronic and daily use, the other patients not expressed a chronic pattern of consumption (data not shown). On the other hand, a negative result does not necessarily indicate a total absence of the drug, since the compound or its metabolites may be present in concentrations below the limit of detection. Additionally, altering agents such as products with a strong base or alkaline salts (bleach) or other strong oxidizing agents can produce flawed results. This information is recorded in the explanatory inserts of each of the tests.

Considering the limitations of the rapid detection tests for substance abuse mentioned above, there is a need to have tools which allow detecting the presence of these drugs in biofluids, in a fast, robust and reliable way. Currently, new solid phase microextraction techniques are being implemented, with matrices compatible with biofluids, specific for extracting compounds of interest and that are efficiently coupled to mass detectors (MS). This technique allows us to quantify within limits of quantification close to $0.5 \mathrm{mg} / \mathrm{mL}^{31}$

Among other possible limitations, the following was found: 1) lack of uniformity among general practitioners, to request the screening for cocaine and other psychotropic drugs, though the process has been dispersed within the medical filed (but this has not been documented); 2) the opportunity to screen for cocaine was not evaluated, nor the application and processing of the cocaine sample, as well as, the time between the first consumption and the processing of the samples for psychotropic substances; the possibility of false negatives notes the importance of these measurements, knowing that in $53 \%$ of the cases testing positive for cocaine, also tested positive for EtOH or BZD (data not shown), and the alteration of consciousness was a frequent symptom during the admission (data not shown), which limited the information regarding the time of consumption; 3) the results, only describe co-consumption among only four substances (EtOH, BZD, cannabis and cocaine) but there are other substances used in combination with cocaine, which were not measured due to the lack of supply by the clinical laboratory (CDO) or because many of the other tests are inappropriate to take relevant clinical decisions in the ER; 4) testing positive for cannabis does not necessarily imply acute consumption; and 55) the analytical findings were not combined with self-reports on the consumption of any type of substances because, due to the effect of the substances consumed, the information and data collected using this method could be considered as a nondifferential classification bias, specifically a memory bias 
caused by the intrinsic property to induce some type of amnesia, mainly in patients who were positive for consumption or exposure to ethanol and benzodiazepines.

\section{Conclusion}

We identified a high frequency of patients attended at the Emergency Room, positive to both ethanol and cocaine, possibly with acute exposure or co-consumption of cannabis or Benzodiazepines. This mixed positivity could be due to an acute co-consumption or multiple exposures of all substances mentioned or could be secondary to chronic consumption of cannabis or Benzodiazepines (1 case) that can be detected at mid to long term, throughout clinical attendance of patients with acute cocaine use or ethanol.

The consumption of psychoactive substances is a problem that has been increasing progressively. Under the effects of these substances, individuals are more likely to go to an ER due to traumatic events, fights, traffic accidents or due to the toxic effects inherent in substance abuse.

The detection tests that are widely available are qualitative, as previously explained. They do not correlate with substance toxicity, do not indicate when or how much substance was consumed or if they are false positives; additionally, in recent years the consumption of alternative psychoactive substances, such as solvents, various amphetamine derivatives, hallucinogens, synthetic cannabinoids, etc., has increased. Unfortunately, there are no accessible tests available in the market for these substances.

It is important for ER physicians, to do a complete anamnesis and physical examination, have complete knowledge regarding all the substances that are available to the consumer, as well as, the toxic effects and clinical parameters they produce. This will help to rationally use the clinical laboratory and assist the clinician without adding an element of confusion.

\section{Acknowledgments}

The authors are grateful to the Clínica del Occidente S.A., and to Dra. Katalina Castañeda and Dr. Julio Acosta for partial support in data collection.

\section{Disclosure}

The authors report no conflicts of interest related to this work.

\section{References}

1. Zyoud S, Waring W, Al-Jabi S, et al. Global cocaine intoxication research trends during 1975-2015: a bibliometric analysis of web of science publications. Subst Abuse Treat Prev Policy. 2017;12(6). doi:10.1186/s13011-017-0090-9.
2. Harbison R, Khlifi M, Zun L, et al. Etiological characterization of acute poisonings in the emergency department. J Emerg Trauma Shock. 2009;2(3):159-163. doi:10.4103/0974-2700.50878

3. Ministerio de Justicia y de Derecho, Ministerio de Salud y Protección Social. Estudio Nacional de consumo de sustancias psicoactivas en Colombia, informe final [National study of psychoactive substance use in Colombia, final report]. Bogota: 2016 [cited August 03, 2018]. Available from: https://www.unodc.org/documents/colombia/2014/ Julio/Estudio_de_Consumo_UNODC.pdf. Accessed July 26, 2019. Spanish.

4. Ministerio de la Protección Social (CO)-OMS/Harvard-FES. Estudio nacional de salud mental, Colombia [National mental health study, Colombia]. Cali: ministerio de la Protección Social; 2015 [cited August 03, 2018]. Available from: https:/www.minsalud.gov.co/ sites/rid/Lists/BibliotecaDigital/RIDE/DE/presentacion-encuestanacional-salud-mental-2015.pdf. Accessed July 26, 2019. Spanish.

5. Hayase T, Yamamoto Y, Yamamoto K. Role of cocaethylene in toxic symptoms due to repeated subcutaneous cocaine administration modified by oral doses of ethanol. J Toxicol Sci. 1999;24(3):227-235.

6. Herbst ED, Harris DS, Everhart ET, et al. Cocaethylene Formation Following ethanol and cocaine Administration by Different Routes. Exp Clin Psychopharmacol. 2011;19(2):95-104. doi:10.1037/ a0022950

7. Harris DS, Everhart ET, Mendelson J, et al. The pharmacology of cocaethylene in humans following cocaine and ethanol administration. Drug Alcohol Depend. 2003;72(2):169-182. doi:10.1016/ S0376-8716(03)00200-X

8. Hart C, Jatlow P, Sevarino K, et al. Comparison of intravenous cocaethylene and cocaine in humans. Psychopharmacology (Berl.). 2000;149(2):153-162. doi:10.1007/s002139900363

9. Wiener S, Sutijono D, Moon C, et al. Patients with detectable cocaethylene are more likely to require intensive care unit admission after trauma. Am J Emerg Med. 2010;28(9):1051-1055. doi:10.1016/ j.ajem.2009.06.014

10. Foltin R, Fischman M. Ethanol and cocaine interactions in humans: cardiovascular consequences. Pharmacol Biochem Behav. 1989;31 (4):877-883. doi:10.1016/0091-3057(88)90399-1

11. Ospina J, Herrera G, Manrique F. Illegal psychoactive substance consumption amongst older schoolchildren in the city of Tunja, Colombia. Rev Salud Publica (Bogota). 2012;14Suppl 2:86-99. doi:10.1590/S0124-00642012000800008

12. El Tiempo. Un gramo de cocaína vale 500 dólares en Pekín [One gram of cocaine is costs $\$ 500$ in Beijing]. Bogotá: Diario El Tiempo; 2018 [cited August 05, 2018]. Available from: https://www.eltiempo. com/justicia/un-gramo-de-cocaina-colombiana-vale-500-dolares-enpekin-64254. Accessed July 26, 2019. Spanish.

13. Vanek VW, Dickey-White HI, Signs SA, et al. Concurrent use of cocaine and alcohol by patients treated in the emergency department. Ann Emerg Med. 1996;28(5):508-514. doi:10.1016/s0196-0644(96)70114-2

14. Teherán AA, Alfonso LE, Ávila A, et al. Mortalidad y estancia hospitalaria relacionada con trauma ocupacional atendido durante el fin de semana en el servicio de emergencias, Bogotá 2007-2010 [Mortality and hospital stay related to occupational trauma attended during the weekend in the emergency service Bogota 2007-2010]. Revista Cuarzo. 2017;23(2):16-25.

15. Patiño $\mathrm{N}$ Laboratorios de toxicología clínica [Clinical toxicology laboratories]. Bogota. [cited August 05, 2018]. Available from: https://encolombia.com/medicina/guiasmed/u-toxicologicas/laborator ios-de-toxicologia/. Accessed July 26, 2019. Spanish.

16. Alcaldía mayor de Bogotá. Bogotá y sus localidades [Bogota and its localities]. Bogotá; 2017 [cited August 05, 2018]. Available from: http://www.culturarecreacionydeporte.gov.co/es/bogotanitos/bogoda tos/bogota-y-sus-localidades. Accessed July 26, 2019. Spanish.

17. Mena U. Localidad de Kennedy, ficha básica [Kennedy locality, basic tab]. Bogota: Secretaría Distrital de cultura, recreación y deportes; 2008 [cited Aug 05, 2018]. Available from: http://www.culturarecrea 
cionydeporte.gov.co/observatorio/documentos/localidades/kenedy. pdf. Accessed July 26, 2019. Spanish.

18. DANE. Censo General 2005 Perfil Localidad Kennedy - Bogotá [General Census 2005 Profile Kennedy Locality - Bogota]. Bogota; 2005 [cited August 05, 2018]. Available from: https://www.dane.gov.co/files/ censo2005/perfiles/bogota/kennedy.pdf. Accessed July 26, 2019. Spanish.

19. Alcaldía mayor de Bogotá, UNODC, Cicad, OEA. Estudio de consumo de sustancias psicoactivas en Bogotá [Study of the consumption of psychoactive substances in Bogota]. Bogota; 2016 [cited August 05, 2018]. Available from: http://www.odc.gov.co/Portals/1/publicaciones/ pdf/consumo/estudios/locales/CO031052016-estudio-consumo-sustan cias-psicoactivas-bogota-2016.pdf. Accessed July 26, 2019. Spanish.

20. Alcaldía mayor de Bogotá. Diagnóstico local con participación social [Local diagnosis with social participation]. Bogota; 2014 [cited August 05, 2018]. Available from: http://www.saludcapital.gov.co/ DSP/Diagnsticos\%20Locales/Locales\%20Preliminares/08_Kennedy. pdf. Accessed July 26, 2019. Spanish.

21. Alcaldía mayor de Bogotá, Instituto Distrital de Gestión de Riesgos y Cambio Climático. Caracterización general de escenarios de riesgo en la localidad Kennedy [General characterization of risk scenarios in the Kennedy locality]. Bogota; 2018 [cited August 05, 2018]. Available from: http://www.idiger.gov.co/documents/220605/314085/Identificaci\% C3\%B3n+y+priorizaci\%C3\%B3n.pdf/24386a78-ea2b-4abe-95169b9c37955fc4. Accessed July 26, 2019. Spanish.

22. Rodríguez T, Racamonde I, González I, et al. Alcohol and cocaine coconsumption in two European cities assessed by wastewater analysis. Sci Total Environ. 2015;536:91-98. doi:10.1016/j.scitotenv.2015.07.016

23. Pennings E, Leccese A, Wolff F. Effects of concurrent use of alcohol and cocaine. Addiction. 2002;97(7):773-783.
24. Moura HF, Benzano D, Pechansky F, et al. Crack/cocaine users show more family problems than other substance users. Clinics (Sao Paulo). 2014;69(7):497-499. doi:10.6061/clinics/2014(07)10

25. Lamptey J. Socio-demographic characteristics of substance abusers admitted to a private specialist clinic. Ghana Med J. 2005;39(1):2-7.

26. Guimarães R, de Castro VDOL, de Oliveira SMDVL, et al. Gender differences in patterns of drug use and sexual risky behaviour among crack cocaine users in Central Brazil. BMC Psychiatry. 2017;17:412. doi:10.1186/s12888-017-1489-6

27. Ministerio de Salud y Protección Social. Ciclo de vida [Lifecicle]. Bogota: Gobierno de Colombia. [cited August 10, 2018]. Available from: https://www.minsalud.gov.co/proteccionsocial/Paginas/ cicloVida.aspx. Accessed July 26, 2019. Spanish.

28. Butler AJ, Rehm J, Fischer B. Health outcomes associated with crack-cocaine use: systematic review and meta-analyses. Drug Alcohol Depend. 2017;180:401-416. doi:10.1016/j.drugalcdep. 2017.08.036

29. Becker J, Hu M. Sex differences in drug abuse. Front Neuroendocrinol. 2008;29(1):36-47. doi:10.1016/j.yfrne.2007.07.003

30. Korte T, Pykäläinen J, Lillsunde P, et al. Comparison of RapiTest with Emit d.a.u. and GC-MS for the analysis of drugs in urine. J Anal Toxicol. 1997;21(1):49-53. doi:10.1093/jat/21.1.49

31. Vasiljevic T, Gómez GA, Pawliszyn J. Single-use poly(etheretherketone) solid-phase microextraction-transmission mode devices for rapid screening and quantitation of drugs of abuse in oral fluid and urine via direct analysis in real-time tandem mass spectrometry. Anal Chem. 2018;90(1):952-960. doi:10.1021/acs.analchem.7b04005 


\section{Supplementary material}

Table SI Frequency of visits to emergency room (ER), toxicological screening, and positive to cocaine during the period of research

\begin{tabular}{|c|c|c|c|c|c|}
\hline Year & Month & ER visits & Toxicology screened & Cocaine positive & Cocaine negative \\
\hline 2016 & January & 14,533 & 24 & 5 & 19 \\
\hline 2016 & February & 15,850 & 27 & 5 & 22 \\
\hline 2016 & March & 14,432 & 35 & 2 & 33 \\
\hline 2016 & April & 13,479 & 17 & 3 & 14 \\
\hline 2016 & May & 14,034 & 24 & 2 & 22 \\
\hline 2016 & June & 13,113 & 20 & I & 19 \\
\hline 2016 & July & 12,076 & 31 & 2 & 29 \\
\hline 2016 & August & 12,792 & 17 & 3 & 14 \\
\hline 2016 & September & 11,852 & 28 & 2 & 26 \\
\hline 2016 & October & 13,118 & 27 & 3 & 24 \\
\hline 2016 & November & 12,584 & 21 & 2 & 19 \\
\hline 2016 & December & 11,854 & 27 & 3 & 24 \\
\hline 2017 & January & 11,554 & 16 & 3 & 13 \\
\hline 2017 & February & 12,365 & 24 & 3 & 21 \\
\hline 2017 & March & 14,122 & 23 & 2 & 21 \\
\hline 2017 & April & 12,068 & 30 & 2 & 28 \\
\hline 2017 & May & 13,789 & 26 & 4 & 22 \\
\hline 2017 & June & 11,700 & 26 & 5 & 21 \\
\hline 2017 & July & 12,599 & 29 & 5 & 24 \\
\hline 2017 & August & 12,065 & 37 & 5 & 32 \\
\hline 2017 & September & $|2,35|$ & 27 & 4 & 23 \\
\hline 2017 & October & 12,775 & 30 & I & 29 \\
\hline 2017 & November & $|2| 2 \mid$, & 38 & 7 & 31 \\
\hline 2017 & December & 10,358 & 48 & 10 & 38 \\
\hline
\end{tabular}

The Open Access Emergency Medicine is an international, peerreviewed, open access journal publishing original research, reports, editorials, reviews and commentaries on all aspects of emergency medicine. The manuscript management system is completely online and includes a very quick and fair peer-review system, which is all easy to use. Visit http://www.dovepress.com/testimonials.php to read real quotes from published authors. 